\title{
Stigma and Trust Among Mental Health Service Users
}

\begin{abstract}
This paper investigates whether and how the stigma experiences of mental health service users relate to trust in the professionals caring for them, and how both stigma and trust relate to service user satisfaction. The study uses survey data gathered from mental health service users $(N=650$ service users from 36 organizations) and applies multilevel regression analyses. The results show that service users with more stigma experiences report less trust and are, partially for that reason, less satisfied with the services. Furthermore, service users with more severe symptoms and those with a psychotic disorder seem the most vulnerable ones for the processes occurring.
\end{abstract}

\section{BACKGROUND}

Numerous studies have shown that the stigma associated with being labeled mentally ill has negative consequences for a variety of outcomes, including self-esteem (Verhaeghe, Bracke, \& Bruynooghe, 2008; Wright, Gronfein, \& Owens, 2000), self-efficacy (Markowitz, 1998), life satisfaction (Rosenfield, 1997), and treatment continuation (Sirey et al., 2001). An outcome that has been largely ignored in the stigma research, is trust in service providers. The concept of trust has also been highly neglected in mental health services research and little is known about its correlates (Brown, Calnan, Scrivener, \& Szmukler, 2009). This empirical study investigates whether stigma experiences among mental health service users relates to trust in mental health nurses and other professional service providers. Furthermore, we explore the relationship of stigma and trust to service user satisfaction.

\section{Trust as a Neglected Concept in Mental Health Services Research}

Research has shown that the quality of the interaction between service users and health professionals is an important element furthering positive outcomes in health care. Several authors 
studying general health care have stressed the crucial importance of interpersonal trust in this relationship (Mechanic, 1998; Thorne \& Robinson, 1988; Zazzali, 2003). Compared to general health care, research in the domain of mental health care has given little attention to trust (Brown et al., 2009; Laugharne \& Priebe, 2006; Piippo \& Aaltonen, 2008). This is surprising, as the interaction between providers and users is considered the most important process that occurs in mental health services (Rosenheck, 2001; Slade, Kuipers, \& Priebe, 2002; Tansella \& Thornicroft, 1998).

Numerous definitions of trust exist (Hall, Camacho, Dugan, \& Balkrishnan, 2002; Hall, Dugan, Zheng, \& Mishra, 2001; Johns, 1996). Based on a literature review, Hall et al. (2001, p. 615) conclude that the majority of these definitions stress "the optimistic acceptance of a vulnerable situation in which the truster believes the trustee will care for the truster's interests." Beliefs about fidelity, competence, honesty, confidentiality, and global trust are important aspects of trust (Hall et al., 2001). In this study, we focus on the trust that mental health service users have in the professional staff members caring for them. Trust is conceptualized as the belief that service providers will care for them properly and, more specifically, that providers will be competent and honest, pursue the interests of service users, and protect private information.

\section{The Relationship Between Stigma and Trust}

Because there is a scarcity of empirical studies dealing with trust among mental health service users, we know little about factors related to trust. This article focuses on one particular aspect that may be associated with trust in service providers: stigma. Stigma has been defined as "an attribute that is deeply discrediting" and that reduces the bearer "from a whole and usual person to a tainted, discounted one" (Goffman, 1963, p. 3). A more recent definition, formulated by Link and Phelan (2001) and often applied, indicates that stigma occurs "when elements of labeling, stereotyping, separation, status loss and discrimination co-occur in a power situation that allows them to unfold" (Link \& Phelan, 2001, p. 367). 
Several theoretical perspectives have demonstrated the negative consequences stigma may have for people with mental health problems. The original labeling perspective (Scheff, 1966) shows how being labeled mentally ill forces people into the role of psychiatric patient. On the one hand, this labeling process occurs within the mental health care setting when service users interact with service providers (Scheff, 1966). On the other hand, labeled people experience negative reactions outside the care setting, such as being excluded from job opportunities and having friendships negatively affected. This mechanism accords with the mechanism described in the public stigma process (Corrigan \& Watson, 2002), which reveals how negative stereotypes about persons with mental health problems lead to negative attitudes towards them, which then results in negative behaviors such as distancing (Angermeyer \& Matschinger, 2005). Whereas the original labeling perspective and the public stigma process consider people with mental health problems as rather passive actors, other perspectives attribute a more active role to them, stressing the subtler stigma mechanisms taking place in the process. The basic assumption is that even if other people are not aware of the stigmatizing condition, stigma may still have an effect. For example, Corrigan's selfstigma theory (Corrigan \& Watson, 2002) explains how internalized stereotypes and attitudes about mental health problems may cause feelings of shame and inferiority in those people who experience mental health problems. Because of these feelings, many people with mental health problems are discouraged about taking initiative in activities such as applying for a job. Another theory that refers to the more subtle stigma mechanisms is Link's modified labeling perspective (Link, Struening, Cullen, Shrout, \& Dohrenwend, 1989). People who expect to be devalued and discriminated against because they have been labeled as mentally ill try to avoid these negative reactions using strategies such as secrecy and withdrawal. However, studies have shown that these strategies cannot reduce the negative consequences of stigma (Link, Mirotznik, \& Cullen, 1991).

Theoretical perspectives about stigma often mention the detrimental effect it has on social relationships. One of the first authors to write about stigma was Goffman, who stressed that stigma should be considered a phenomenon that affects interactions between people (Goffman, 1963). 
Jones (1984) spoke of stigma in terms of "marked relationships." A large body of empirical research has confirmed the public stigma process, showing how negative attitudes among the general public result in a distancing from those with mental health problems (e.g., Angermeyer \& Matschinger, 2005). In addition, Link (1989) argues that stigma expectations may lead service users themselves to withdraw from social relationships. Empirical studies investigating the link between the stigma experiences of mental health service users and their social relationships from the perspective of service users are relatively scarce, however, and primarily focus on relationships with people outside the treatment setting (e.g., Link et al., 1989; Prince \& Prince, 2002). The study of negative effects of stigma on interactions within mental health services is often neglected, which is surprising since early writings about stigma have shown them to play a crucial role (Goffman, 1961, 1963; Scheff, 1966) and because they are also mentioned in more recent theoretical approaches.

Studies like Corrigan and Watson (2002) and others have shown that service users with stigma experiences often distance themselves from others or withdraw from social relationships in general (Corrigan \& Watson, 2002; Link, Yang, Phelan, \& Collins, 2004). Furthermore, there are reasons to expect that mental health service users will distance themselves especially from others who they associate with mental health problems, such as other service users or mental health professionals. Stigma experiences may thus result in more feelings of distrust towards mental health professionals. We can apply this general reasoning to several types of stigma experiences, in accordance with the several underlying theoretical perspectives.

First, we believe, in accordance with the original labeling perspective and the public stigma process, that service users who experience more public stigma might have more negative emotional reactions such as fear or shame, which may lead to more distrust. Second, we assume that, in accordance with Corrigan's (2002) self-stigma theory, we will find that greater feelings of shame and inferiority will be related to more distrust, independent of concrete public stigma experiences. Third, Link's modified labeling perspective (1989) reveals that labeled people may adapt their behavior out of fear of devaluation and discrimination, even if they do not believe the stereotypes and have no 
concrete experiences of public stigma. Therefore, we assume that stigma expectations will be negatively related to trust in mental health service providers independently of public stigma and self-stigma.

\section{Stigma, Trust, and Service User Satisfaction}

This study will also investigate the link between stigma and trust on one hand, and between both stigma and trust and service user satisfaction on the other. Although stigma is considered a barrier to recovery for mental health service users (Link, Struening, Neese-Todd, Asmussen, \& Phelan, 2001), the precise intermediate mechanisms that occur within mental health service organizations remain unclear. Since the interaction between service users and providers is a main process within mental health services (Slade et al., 2002), and trust is viewed as a main characteristic of this interaction (Mechanic, 1998; Thorne \& Robinson, 1988; Zazzali, 2003), trust may be considered a potentially important intermediate variable linking stigma to outcomes of mental health services. In this study, we will consider the outcome variable service user satisfaction.

\section{Summary of Research Hypotheses}

To summarize, in accordance with the theoretical reasoning of the original labeling perspective, the self-stigma theory, and the modified labeling perspective, we hypothesize that public stigma, self-stigma, and stigma expectations, will be found to negatively relate to mental health service users' trust in mental health professionals independently of each other.

Furthermore, we hypothesize that trust in mental health professionals will be positively related to service user satisfaction. Finally, we assume that trust in mental health professionals will partially explain the link between stigma and service user satisfaction.

\section{Methods}

\section{Subjects}


For our research into the relationship between stigma, trust, and client satisfaction, we used survey data we gathered in 2005 for a larger study on stigma in mental health services in Flanders, the Dutch-speaking part of Belgium. In Belgium, mental health care is organized into different care trajectories for different target groups according to criteria such as age and the presence of cognitive disorders. Because the focus of the study was on adults with mental health problems, it was necessary to exclude organizations and wards if their services were aimed exclusively at service users younger than 18 or older than 60 or 65 (depending on the usual criteria of the center), or were aimed exclusively at service users with cognitive disorders (as defined on axis 1 of the DSM IV) or mental retardation. Five types of mental health services were enrolled. Out of a total population of 215 organizations, 46 were selected. After 10 refusals, the final sample included 36 mental health centers: 8 psychiatric hospitals, 7 general hospitals, 8 day activity centers, 7 psychiatric rehabilitation centers, and 6 community mental health centers. Within these selected centers, the following service users were excluded: those with cognitive disorders or mental retardation, those in a stage of illness too acute to enable them to participate (determined by the staff), and those with insufficient knowledge of Dutch. Of the 1,174 eligible service users, $846(72 \%)$ agreed to fill out anonymously a structured questionnaire, which took an average of 45 minutes. The final working sample for this study consisted of 650 service users, as cases with missing values on one or more of the variables in the analyses were excluded from the analyses. The Ethical Committee of the faculty the authors are affiliated with approved the study. Informed consent was obtained from the participants after an introduction by the researcher. Information about reasons for refusal and about the characteristics of the refusing service users is unavailable, due to ethical considerations and privacy legislation.

\section{Measures}

Dependent and intermediate variables. Service user satisfaction was operationalized using a Dutch version of the Client Satisfaction Questionnaire-8 (Nguyen et al., 1983; De Brey, 1983), which 
is one of the unidimensional scales most often used for measuring satisfaction in a large diversity of mental health services (e.g., Priebe et al., 2007). The scores on eight items, ranging from 1 to 4 , were averaged to obtain a global satisfaction score $(M=3.08 ; S D=0.53$; alpha $=0.89)$.

Trust refers to the trust that service users have in the professionals caring for them and was operationalized using a measure inspired by the Trust in Physician Scale (Anderson \& Dedrick, 1990; Thom, Ribisl, Stewart, \& Luke, 1999), one of the scales most often used for measuring trust in general health care. We slightly adapted the scale to make it more applicable to mental health care, omitting referrals to "medical" and "treatment" as many mental health service users do not acknowledge having a "medical" health problem that should be "treated." Furthermore, the instrument was shortened to five items, as it had been included in a larger survey with several other instruments. The five items each represent one dimension of trust, as definedby Hall et al. (2001). Fidelity was measured as "I have confidence that they know what is best for me," competence as "They are capable of dealing with my problems," honesty as "If they say something, I will believe it," confidentiality as "I think they sometimes gossip about my private life," reverse scored, and global trust as "I always try to follow their advice." The instrument has five answer categories ranging from strongly disagree (1) to strongly agree (5). The global measure was computed as the average of the $\operatorname{scores}(M=3.84 ; S D=0.72 ;$ alpha $=0.79)$.

Independent variables. In accordance with the three theoretical perspectives mentioned above, we included three variables referring to stigma: public stigma, self-stigma, and stigma expectations. Public stigma was operationalized as the mean score of 5 items, with scores ranging from 1 to 5, adapted from Fife and Wright's social rejection subscale (2000) ( $M=3.10 ; S D=1.22$; alpha $=0.91)$. An example item is "Since I come to this center, some people treat me with less respect." Self-stigma was computed as the mean score of 5 items based on the social isolation subscale of Fife and Wright $(M=2.73 ; S D=1.28$; alpha $=0.92)$. An example is "Since I come to this center, I have come to feel inferior." Stigma expectations were measured using the 12 items from Link's Devaluation-Discrimination scale (1987). We broadened its scope to include all persons who 
receive(d) psychological help, as suggested by Link, Struening, Neese-Todd, Asmussen and Phelan (2002). The scores, from 1 to 4 , were averaged to obtain a total score $(M=2.70 ; S D=0.42 ;$ alpha $=$ $0.83)$.

Background variables. Besides the main independent variables, several background variables were considered. We measured symptoms using the mean score (from 0 to 4 ) of the 18 items from the Brief Symptom Inventory-18 (Derogatis, 2001), using the Dutch translation (Arrindell \& Ettema, 1986) of the items of the SCL-90-R $(M=1.42 ; S D=0.93$; alpha $=0.94)$. To measure diagnosis, three main diagnostic categories were used as dichotomous variables $(1=$ present; $0=$ absent): psychotic, mood-related, and substance-related disorders. The number of years since first treatment was computed as the difference between current age and age at the first professional mental health treatment. Length of the current treatment period was measured in months, whereas intensity of current treatment counted the hours per week a service user spent at the current center. Finally, some general background variables were taken into account: gender (men $=2$; women $=1)$, age (in years) and marital status (married or cohabiting $=1$; single, divorced, or widowed $=0$ ). Education was measured using four categories (primary degree $=1$; college degree $=4$ ), while income was operationalized through a proxy variable that asks the service users how easily they can get by with the money they have at their disposal; responses were measured on a continuum from 1 (very difficult) to 6 (very easy).

Analysis. Because of the clustered nature of our data, we performed multilevel regression analyses using the Mixed Models procedure in the program SPSS 15. First, we investigated determinants of trust. After the background variables were introduced, the stigma variables were added. Second, we explored the effects of the independent variables on service user satisfaction. The variables were added to the analyses in the following sequence: background variables, stigma variables, and finally, trust.

\section{RESULTS}


Table 1 describes the working sample: 361 (55.5\%) of service users are women, and age varies from 16 to 73 , with an average of 39 . A quarter of the respondents are married or cohabiting $(N=164)$, and $214(33 \%)$ service users have a mood disorder, $165(21 \%)$ a psychotic disorder, and $182(28 \%)$ a substance disorder.

TABLE 1

The results show that several background variables are significantly related to trust (Table 2 , Model 1A). First, older service users have more trust in their service providers than younger ones (coeff. $=0.118 ; p=0.01$ ). This finding agrees with the results from other empirical studies on trust (Hall et al., 2001). Furthermore, service users with more psychiatric symptoms (coeff. $=-0.131 ; p=$ 0.002 ) and those with psychotic disorders (coeff. $=-0.112 ; p=0.012$ ) have less trust in staff members. Finally, service users receiving more intensive care also have less trust in service providers (coeff. $=-0.143 ; p<0.001)$.

\section{TABLE 2}

When introducing the stigma variables (Model 1B), we see that service users who expect devaluation and discrimination (coeff. $=-0.146 ; p<0.01$ ) and those with more self-stigma experiences (coeff. $=-0.172 ; p<0.001$ ) have less trust in their service providers. Our data does not support the hypothesis that public stigma experiences have an independent effect on trust.

Furthermore, the aforementioned relationship between symptoms and trust is no longer significant after the introduction of stigma (coeff. $=-0.025 ; p>0.05$ ). This result shows that service users with more symptoms have less trust in their service providers because they have higher stigma expectations and more self-stigma experiences. In other words, service users with more symptoms seem to have a greater fear of devaluation and discrimination and have more feelings of shame and inferiority, which results in less trust in their service providers.

Our second research question deals with the effect of the stigma variables and trust on service user satisfaction. First, for the stigma variables (Model 2B), only self-stigma is significantly related to service user satisfaction (coeff. $=-0.215 ; p<0.001$ ). This means that service users with 
more feelings of fear and inferiority due to attending a mental health service organization are less satisfied with the services received. Furthermore, self-stigma partially explains the relationship between several background variables and service user satisfaction. Service users with more symptoms, those with a more intensive treatment, and those with a psychotic disorder are less satisfied, in part because they have more self-stigma.

In the last step, we added trust to the analyses (Model 2C). The results show a strong effect of trust on service user satisfaction (coeff. $=0.404 ; p<0.001$ ). In our analyses, trust is the most important determinant of satisfaction: the more trust service users have in their professional service providers, the more satisfied they are with the services they receive. When exploring the relationships between stigma, trust, and service user satisfaction, two other interesting results concerning the stigma variables appear. First, the effect of self-stigma on client satisfaction is partially attributable to trust, as the size of the coefficient diminishes with a third (from -0.215 to 0.145). Therefore, service users with more feelings of self-stigma are less satisfied with services, partially because they have less trust in the service providers. A second finding is the appearance of a suppressor effect. When controlling for trust, a significant positive effect of stigma expectations appears (coeff. $=0.06 ; p<0.05$ ), showing that service users with more stigma expectations are more satisfied when accounting for trust. Finally, when trust is introduced, two interesting results concerning the background variables appear (Model 2C). First, the positive effect of age on service user satisfaction is no longer significant (coeff $=0.018 ; p<0.05$ ), which suggests that older service users are more satisfied with the services they receive because they have more trust in service providers. Second, the negative effect of having a psychotic disorder is no longer significant when taking trust into account (coeff. $=-0.050 ; p<0.05$ ). This suggests that service users with a psychotic disorder are less satisfied with services because they have less trust in the service providers.

\section{Discussion and Conclusion}


This empirical study, based on hypotheses that are in accordance with the three main theoretical perspectives dealing with the stigma of mental illness, investigated the link between three types of stigma experiences and trust. Furthermore, this study investigated the effects of each of the three stigma variables and trust on service user satisfaction.

We believe that this study yields some important results. First, we found that stigma experiences are associated with less trust. More specifically, service users with more expectations of devaluation and discrimination and those with more self-stigma experiences have less trust in staff members. These findings are in line with the reasoning of both the modified labeling perspective (Link et al., 1989) and the self-stigma theory (Corrigan \& Watson, 2002), showing how subtle stigma mechanisms may exert an effect through emotional reactions such as fear and shame. These emotions seem to affect the interactions between service users and mental health professionals. Interestingly, stigma expectations and self-stigma have effects on trust independently of each other. This finding implies that stigma expectations can induce feelings of distrust, even if service users have not internalized stigmatizing cognitions or attitudes and thus do not feel ashamed and inferior because of attending a mental health service organization. We found no effect of public stigma experiences, however, which means that we could not confirm the process as expected from the original labeling perspective (Scheff, 1966) and the public stigma process (Angermeyer \& Matschinger, 2005). This finding suggests that distrust among service users does not occur as a reaction to concrete experiences of devaluation or rejection by their environment. In other words, the results suggest that service users may have higher levels of distrust in mental health professionals due to stigma expectations and self-stigma, despite an absence of any concrete negative reaction from other people. Regarding the relationship between background variables and trust, we found that the relationship between symptoms and trust is no longer significant after the introduction of stigma. This finding suggests that service users with more symptoms have less trust in their service providers because they have higher stigma expectations and more self-stigma experiences, that is, service users with more symptoms seem to have more fear of devaluation and 
discrimination and more feelings of shame and inferiority, which in turn results in less trust in their service providers.

Furthermore, our results confirmed the importance of trust for service user satisfaction, as it was the most important determinant of service user satisfaction. This strong relationship between trust and satisfaction is in accordance with the findings of other studies in health care (e.g., LaVeist, Nickerson, \& Bowie, 2000) and of studies in other domains (e.g., Dirks \& Ferrin, 2001; Van Houtte, 2006).

Another important result concerns the relationship between stigma, trust, and service user satisfaction. Self-stigma and distrust were found to be related to dissatisfaction, and lower trust can partially explain why those service users who report more self-stigma are less satisfied. The results also showed that trust suppresses the positive association between stigma expectations and service user satisfaction. One possible interpretation of this suppressor effect is that distrust prevents service users with more stigma expectations from being more satisfied. It is plausible that service users with more stigma expectations have fewer positive expectations about mental health services, as they generally expect to be discriminated against and devalued. Because of these generally low expectations, they may be relatively satisfied with the services received. However, stigma expectations seem to induce feelings of distrust towards the professionals, and the suppressor effect suggests that this distrust impedes the positive relationship between stigma expectations and satisfaction.

There are some limitations that may affect the results of this study. First, we used only crosssectional data. Other causal directions than the ones we assumed are possible. For example, it is plausible that service users who have had bad experiences in their current mental health care setting and are thus less satisfied will report less trust in their mental health professionals. Longitudinal data are needed to draw clearer conclusions about the causal direction of the relationships we found. Second, other variables that are not included in our study might play an important role. For example, we have no indicator of generalized distrust. Service users who distrust the professionals may be 
characterized by more feelings of distrust in general, which could lead to more experiences of negative interactions with other people and to more reports of stigma expectations. Future research should try to disentangle trust in specific persons or groups from general trust, as suggested by Hall et al. (2001). Third, one could suppose that the interrelationships between stigma, trust, and service user satisfaction are due to the use of self-report measures. Service users who generally experience many negative feelings may score higher on stigma, dissatisfaction, and distrust because they tend to report negatively on all questions. However, we have tried to avoid this problem as much as possible by including an indicator of the severity of symptoms. Another shortcoming is the lack of a more elaborate instrument of trust and service user satisfaction. For example, other studies have presented trust as a multidimensional construct, with dimensions referring to fidelity, confidence, competence, honesty, and global trust (Hall et al., 2001). Our instrument was very short and contained only one item for each dimension. Furthermore, the analyses did not focus on differences between organizations although different service contexts are included. However, it is beyond the scope of this paper to investigate whether stigma, trust, and service user satisfaction differ between services or to explore how they relate to structures and processes that are part of the organization of mental health care. However, we believe that this is a promising area for future research. Another limitation is that we cannot exclude selection effects. As indicated earlier, $72 \%$ of eligible service users wanted to participate in our survey. Although this is a relatively high number, we cannot assume that they are completely representative of all eligible service users. Due to ethical considerations and privacy legislation, no data could be gathered about the service users who refused to participate. However, we assume that service users with more feelings of general distrust or of distrust in mental health professionals would be more inclined to refuse to participate in a survey. On the other hand, service users with more stigma experiences as well as those who are more dissatisfied may refuse more. Therefore, it is possible that our findings underestimate these relationships. 
Despite these limitations, we believe that this empirical study has several merits. First, our study is one of the first empirical studies to deal with trust within mental health care settings. Second, to our knowledge it is the first empirical study to link stigma with trust in mental health services. Moreover, in accordance with the approach of the three main theoretical perspectives on the stigma of mental illness we distinguish between three types of stigma experiences. Another merit is the large number of service users involved in the study. Furthermore, we believe that the agreement of several of our results with other studies on trust in other contexts contributes to the validity of our study.

We believe that our results give insight into one of the ways in which stigma exerts its effects within mental health services. Although several studies have shown that stigma has negative consequences for mental health service users (Markowitz, 1998; Rosenfield, 1997; Sirey et al., 2001; Verhaeghe et al., 2008; Wright, Gronfein, \& Owens, 2000), few studies (e.g., Raingruber, 2002) address the precise mechanisms related with stigma that occur within mental health services. We therefore suggest that the lack of trust in mental health professionals deserves greater attention in future research.

Additionally, we believe that psychiatric nurses and other mental health professionals should pay explicit attention to trust and stigma as important forces within mental health care settings. They should pay special attention to the more subtle social psychological stigma mechanisms. Furthermore, our study suggests that some service users - those with higher levels of symptoms and those with psychotic disorders-are more vulnerable to the processes we have discussed. When developing a program or when developing strategies to deal with stigma and/or distrust among mental health service users, these specifically vulnerable service users deserve special attention.

To conclude, we believe that trust should not be considered just another outcome that might be affected by stigma. It might be a potentially crucial outcome, given the importance of trust in human relationships in general, and the importance of social interaction in mental health services. 


\section{Reference List}

Anderson, L. A., \& Dedrick, R. F. (1990). Development of the Trust in Physician Scale-A measure to assess interpersonal-trust in patient-physician relationships. Psychological Reports, 67, 1091-1100.

Angermeyer, M., \& Matschinger, H. (2005). Labeling-stereotype-discrimination. An investigation of the stigma process. Social Psychiatry and Psychiatric Epidemiology, 40, 391-395.

Arrindell, W. A., \& Ettema, J. H. M. (1986). SCL-90. Handleiding bij een multidimensionele psychopathologie-indicator. Lisse: Swets \& Zeitlinger.

Brown, P., Calnan, M., Scrivener, A., \& Szmukler, G. (2009). Trust in mental health services: A neglected concept. Journal of Mental Health, 18, 449-458.

Corrigan, P. W., \& Watson, A. C. (2002). The paradox of self-stigma and mental illness. Clinical Psychology-Science and Practice, 9, 35-53.

De Brey, H. (1983). A cross-national validation of the client satisfaction questionnaire: The Dutch experience. Evaluation and Program Planning, 6, 395-400.

Derogatis, L. R. (2001). BSI-18: Administration, scoring and procedures manual. Minneapolis: National Computer Systems.

Dirks, K. T., \& Ferrin, D. L. (2001). The role of trust in organizational settings. Organization Science, 12, 450-467.

Fife, B. L., \& Wright, E. R. (2000). The dimensionality of stigma: A comparison of its impact on the self of persons with HIV/AIDS and cancer. Journal of Health and Social Behavior, 41, 50-67.

Goffman, E. (1961). Asylums: Essays on the social situation of mental patients and other inmates. London: Penguin Books.

Goffman, E. (1963). Stigma : Notes on the management of spoiled identity. Englewood Cliffs, NJ: Prentice-Hall.

Hall, M. A., Camacho, F., Dugan, E., \& Balkrishnan, R. (2002). Trust in the medical profession: Conceptual and measurement issues. Health Services Research, 37, 1419-1439. 
Hall, M. A., Dugan, E., Zheng, B. Y., \& Mishra, A. K. (2001). Trust in physicians and medical institutions: What is it, can it be measured, and does it matter? Milbank Quarterly, 79, 613-639.

Johns, J. L. (1996). A concept analysis of trust. Journal of Advanced Nursing, 24, 76-83.

Jones, E. E., Farina, A., Hastorf, A. H., Markus, H., Miller, D. T., Scott, R. A. et al. (1984). Social stigma. The psychology of marked relationships. New York: W.H. Freeman and Company.

Laugharne, R., \& Priebe, S. (2006). Trust, choice and power in mental health. Social Psychiatry and Psychiatric Epidemiology, 41, 843-852.

LaVeist, T. A., Nickerson, K. J., \& Bowie, J. V. (2000). Attitudes about racism, medical mistrust, and satisfaction with care among African American and white cardiac patients. Medical Care Research and Review, 57, 146-161.

Link, B. G. (1987). Understanding labeling effects in the area of mental disorders: An assessment of the effects of expectations of rejection. American Sociological Review, 52, 96-112.

Link, B. G., Mirotznik, J., \& Cullen, F. T. (1991). The effectiveness of stigma coping orientations-Can negative consequences of mental illness labeling be avoided. Journal of Health and Social Behavior, 32, 302-320.

Link, B. G., \& Phelan, J. C. (2001). Conceptualizing stigma. Annual Review of Sociology, 27, 363-385.

Link, B. G., Struening, E., Cullen, F. T., Shrout, P. E., \& Dohrenwend, B. P. (1989). A modified labeling theory approach to mental disorders-An empirical assessment. American Sociological Review, 54, 400-423.

Link, B. G., Struening, E., Neese-Todd, M., Asmussen, S., \& Phelan, J. C. (2001). Stigma as a barrier to recovery: The consequences of stigma for the self-esteem of people with mental illnesses. Psychiatric Services, 52, 1621-1626.

Link, B. G., Struening, E., Neese-Todd, S., Asmussen, S., \& Phelan, J. C. (2002). On describing and seeking to change the experience of stigma. Psychiatric Rehabilitation Skills, 6, 201-231. 
Link, B. G., Yang, L. H., Phelan, J. C., \& Collins, P. Y. (2004). Measuring mental illness stigma. Schizophrenia Bulletin, 30, 511-541.

Markowitz, F. E. (1998). The effects of stigma on the psychological well-being and life satisfaction of persons with mental illness. Journal of Health and Social Behavior, 39, 335-347.

Mechanic, D. (1998). The functions and limitations of trust in the provision of medical care. Journal of Health Politics Policy and Law, 23, 661-686.

Nguyen, T. D., Attkisson, C. C., \& Stegner, B. L. (1983). Assessment of patient satisfaction: Development and refinement of a service evaluation questionnaire. Evaluation and Program Planning, 6, 299-313.

Piippo, J., \& Aaltonen, J. (2008). Mental health care: Trust and mistrust in different caring contexts. Journal of Clinical Nursing, 17, 2867-2874.

Priebe, S., McCabe, R., Bullenkamp, J., Hansson, L., Lauber, C., Martinez-Leal, R. et al. (2007). Structured patient-clinician communication and 1-year outcome in community mental healthcare-Cluster randomised controlled trial. British Journal of Psychiatry, 191, 420-426.

Prince, P. N., \& Prince, C. R. (2002). Perceived stigma and community integration among clients of assertive community treatment. Psychiatric Rehabilitation Journal, 25, 323-331.

Raingruber, B. (2002). Client and provider perspectives regarding the stigma of and nonstigmatizing interventions for depression. Archives of Psychiatric Nursing, 16, 201-207.

Rosenfield, S. (1997). Labeling mental illness: The effects of received services and perceived stigma on life satisfaction. American Sociological Review, 62, 660-672.

Rosenheck, R. A. (2001). Organizational process: A missing link between research and practice. Psychiatric Services, 52, 1607-1612.

Scheff, T. J. (1966). Being mentally ill. A sociological theory. (1st ed.) Chicago: Aldine Publishing Company. 
Sirey, J. A., Bruce, M. L., Alexopoulos, G. S., Perlick, D. A., Raue, P., Friedman, S. J. et al. (2001). Perceived stigma as a predictor of treatment discontinuation in young and older outpatients with depression. American Journal of Psychiatry, 158, 479-481.

Slade, M., Kuipers, E., \& Priebe, S. (2002). Mental health services research methodology. International Review of Psychiatry, 14, 12-18.

Tansella, M., \& Thornicroft, G. (1998). A conceptual framework for mental health services: The matrix model. Psychological Medicine, 28, 503-508.

Thom, D. H., Ribisl, K. M., Stewart, A. L., \& Luke, D. A. (1999). Further validation and reliability testing of the Trust in Physician Scale. Medical Care, 37, 510-517.

Thorne, S. E., \& Robinson, C. A. (1988). Reciprocal trust in health-care relationships. Journal of Advanced Nursing, 13, 782-789.

Van Houtte, M. (2006). Tracking and teacher satisfaction, role of study culture and trust. Journal of Educational Research, 99, 247-254.

Verhaeghe, M., Bracke, P., \& Bruynooghe, K. (2008). Stigmatisation and self-esteem of persons in recovery from mental illness: The role of peer support. International Journal of Social Psychiatry, 54, 206-218.

Wright, E. R., Gronfein, W. P., \& Owens, T. J. (2000). Deinstitutionalization, social rejection, and the self-esteem of former mental patients. Journal of Health and Social Behavior, 41, 68-90.

Zazzali, J. L. (2003). Trust. An implicit force in health care organization theory. In S. S. Mick \& M. E. Wyttenbach (Eds.), Advances in health care organization theory (pp. 233-252). San Francisco: John Wiley \& Sons. 


\begin{tabular}{lll}
\hline Table 1 - Description of the sample & & \\
\hline & $\%$ or mean & SD \\
\hline Gender (\% men) & 44.5 & \\
Age & 39.31 & 11.52 \\
Education & 2.94 & 0.76 \\
Income & 3.27 & 1.43 \\
Marital status (\% married or cohabiting) & 25.2 & \\
Symptoms & 1.42 & 0.93 \\
Length current treatment, in months & 16.75 & 31.44 \\
Number of years since first treatment & 10.51 & 8.64 \\
Intensity treatment, hours per week & 78.45 & 67.49 \\
\% Mood-related disorder & 32.92 & \\
\% Psychotic disorder & 20.92 & \\
\% Substance-related disorder & 28.0 & \\
\hline
\end{tabular}


Table 2 - the relationship between background characteristics, stigma, trust and service user satisfaction. Results of a multilevel regression analysis (standardized regression coefficients and significance)

trust

service user satisfaction

\begin{tabular}{|c|c|c|c|c|c|}
\hline & model $1 \mathrm{~A}$ & model 1B & model $2 \mathrm{~A}$ & model 2B & model $2 \mathrm{C}$ \\
\hline Gender (men) & $-0,012$ & $-0,030$ & $-0,103$ * & $-0,084 * *$ & $-0,072 * *$ \\
\hline Age & 0,118 * & $0,134^{* *}$ & 0,065 & 0,072 * & 0,018 \\
\hline Education & $-0,065$ & $-0,054$ & $-0,070$ & $-0,045$ & $-0,023$ \\
\hline Marital status (married or cohabitir & 0,067 & 0,064 & 0,052 & 0,037 & 0,012 \\
\hline Income & 0,041 & 0,024 & 0,089 * & 0,058 * & 0,048 * \\
\hline Symptoms & $-0,131^{* *}$ & $-0,025$ & $-0,215^{* * *}$ & $-0,067^{*}$ & $-0,056$ * \\
\hline Number of years since first treatm & if $\quad-0,007$ & $-0,023$ & 0,053 & 0,012 & 0,021 \\
\hline Length current treatment & $-0,071$ & $-0,061$ & $-0,051$ & $-0,025$ & 0,000 \\
\hline Intensity current treatment & $-0,143 * * *$ & $-0,130 * *$ & $-0,115^{* *}$ & $-0,047$ & 0,006 \\
\hline Mood disorder & 0,011 & 0,002 & $-0,048$ & $-0,041$ & $-0,042$ \\
\hline Psychotic disorder & $-0,112 *$ & $-0,113$ * & $-0,169 * * *$ & $-0,096 * *$ & $-0,050$ \\
\hline Substance disorder & $-0,044$ & $-0,051$ & $-0,053$ & $-0,046$ & $-0,025$ \\
\hline Stigma expectations & & $-0,146 * *$ & & 0,001 & 0,060 * \\
\hline Public stigma & & 0,023 & & $-0,010$ & $-0,019$ \\
\hline Self-stigma & & $-0,172 * * *$ & & $-0,215^{* * *}$ & $-0,145^{* * *}$ \\
\hline Trust & & & & & $0,404^{* * *}$ \\
\hline
\end{tabular}

${ }^{*} p<0,05 ;{ }^{* \star} p<0,01 ;{ }^{* *} p<0,001$ 